\title{
ADULT INFECTIOUS DISEASE NOTES
}

\section{Patient safety: What does it all mean?}

\author{
B Lynn Johnston $\mathrm{MD}^{1}$, John M Conly $\mathrm{MD}^{2}$
}

A number of articles have appeared in the medical literature over the past four years on the topic of patient safety, including a series in the New England Journal of Medicine in 2002 and 2003 (1). There has been considerable media interest, with a number of reports on medical errors and their associated consequences. The Royal College of Physicians and Surgeons of Canada sponsored a National Steering Committee on Patient Safety that published its report in 2002 (2). The committee made 19 recommendations intended to improve patient safety in Canadian health care (2). In 2003, the government of Canada committed $\$ 10$ million/year for implementation of the recommendations, including support for the creation of a Canadian Patient Safety Institute (3). The Canadian Council on Health Services Accreditation has indicated its commitment to playing a major role in improving patient safety through accreditation (4). The Canadian Institutes for Health Information and Health Research have jointly funded the Canadian Adverse Events Study, examining the extent of adverse events in acute care hospitals with results expected to be published in 2004. This study includes 20 teaching, community and small hospitals in five provinces (British Columbia, Alberta, Ontario, Quebec and Nova Scotia). Clearly, patient safety has become a very relevant topic.

From a historical perspective, Elihu Schimmel in 1964 (5) wrote that recent medical progress has brought dramatic advances in methods of diagnosis and treatment but, with each new advance, reports of adverse reactions have soon followed. As a chief resident, he undertook a prospective study of the type and frequency of complications ('episodes') occurring in response to medical care. Episodes occurring as a result of errors were excluded. There were 240 episodes in 198 of 1014 (19.5\%) patients. The majority of episodes $(49.6 \%)$ were reactions to therapeutic drugs, $9.6 \%$ were hospital acquired infections, $20 \%$ were life threatening or fatal, and $6.7 \%$ were fatal. Antimicrobials were associated with $29.4 \%$ of adverse reactions to medications. Six of the 16 deaths (37.5\%) were in patients with hospital-acquired infections.

Thirty-six years later, the Institute of Medicine (IOM) in the United States published To Err is Human: Building a Safer Health System (6). In it, they estimated that between 44,000 and 98,000 Americans die each year as a result of medical errors. These numbers were extrapolated from the results of three studies (7-9) examining the incidence of adverse events in hospitalized patients and have been vigorously debated. In the first two of these studies, investigators retrospectively estimated the incidence and nature of adverse events in patients hospitalized in 51 hospitals in New York State in 1984 $(7,8)$. These studies were prompted by the need for better data on poor quality care and iatrogenic injury in the face of increasing numbers of malpractice claims and damages. The authors estimated the state-wide incidence of adverse events to have been $3.7 \%$, of which $27.6 \%$ were due to negligence, defined as care that fell below the standard expected of physicians in their community (7). Elderly patients were at a higher risk of an adverse event. Certain specialties had higher rates of adverse events (but not negligence) in keeping with inherently higher risk procedures and patients. They further estimated that $13.6 \%$ of the adverse events caused death and extrapolated it to 13,451 deaths in New York State, due at least in part, to the result of adverse events. However, the authors acknowledged that many patients who died after an adverse event had very serious underlying disease and death could have been imminent in any event (7). One-half of the adverse eventrelated deaths were attributed to negligence. Nearly one-half of the adverse events resulted from operations, with wound infections (29\% of surgical complications and $14 \%$ of all adverse events) being the most common surgical adverse event (8). Drug complications were the single most common type of adverse event (19\%) and antimicrobials accounted for $16.3 \%$ of these (8). Using similar methodology, Thomas et al (9) performed a study of patients hospitalized in a random sample of 28 hospitals in Utah and Colorado in 1992. They determined that $2.9 \%$ of hospitalizations were associated with adverse events, with death following $6.6 \%$ of these events. Wound (11.4\%) and nonwound (10\%) infections accounted for $21.4 \%$ of surgery-related adverse events. Among adverse drug events, $24.9 \%$ were due to antibiotics. Notably, rates of adverse drug reactions varied among the different types of hospitals, suggesting that findings from one type of facility may not be generalizable with others. This study also found that inter-rater reliability was only moderate (kappa=0.4). These authors further estimated that health care costs for all adverse events totalled US $\$ 348,081,000$ or $2.5 \%$ per capita of state health care expenditures (10). Postoperative complications and adverse drug events were the most expensive complications.

There has been much debate over the accuracy of the estimates suggested in the IOM report and the way in which they were presented. MacDonald et al (11) pointed out that charts studied were identified by criteria (including death) intended to find patients with a high likelihood of experiencing an

\footnotetext{
${ }^{1}$ Queen Elizabeth II Health Sciences Centre and Dalhousie University, Halifax, Nova Scotia; ${ }^{2}$ Departments of Pathology and Laboratory Medicine,

Medicine, and Microbiology and Infectious Diseases, University of Calgary, Calgary, Alberta

Correspondence and reprints: Dr Lynn Johnston, Department of Medicine, Room 5014 ACC, Queen Elizabeth II Health Sciences Centre,

1278 Tower Road, Halifax, Nova Scotia B3H 2Y9. Telephone 902-473-5553, fax 902-473-7394, e-mail ljohnsto@dal.ca

Received and accepted March 25, 2004
} 
adverse event and that no information about baseline risk of death nor information about deaths in a comparison group were given. Hence, these IOM cited studies were biased towards finding high adverse event and death rates, and could not infer causality. To address the question of how much of a contribution adverse events might have on outcome, Hayward and Hofer (12) had internists review the records of 111 hospital deaths using a previously tested structured implicit review instrument. Physicians estimated that $6 \%$ of deaths were probably or definitely preventable by optimal care, but only $0.5 \%$ who died would have lived at least three months. They concluded that many deaths attributed to medical errors occur at the end of life or in critically ill patients in whom death is the most likely outcome. Brennan (13), a key investigator in these studies, further highlighted fallacies in the IOM's interpretations. Neither study $(7,9)$ upon which the IOM based its estimates, judged whether the adverse events caused death. Additionally, Brennan (13) acknowledged that assessing preventability is difficult, and no one has yet measured the incidence of errors in a general medical population.

Given this background, the merits of the widely anticipated Canadian Adverse Events Study will have to be judged with an appreciation of the strengths and weaknesses of the study methods employed. Most such studies involve two-stage chart review of a random selection of patient charts (7-9). Trained nurses or medical record administrators screened all the selected records using established criteria to identify patients that could have experienced an adverse event. Nurse screening is felt to have a high sensitivity at $84 \%$ (9). Physicians then review records that meet any of the screening criteria, using a structured chart abstraction form, to determine if an adverse event occurred. An adverse event is usually defined as an injury caused by medical management that resulted in prolonged hospital stay, disability at discharge or death (14). Adverse events may be further assessed for preventability and type of injury. One study to measure reliability of medical record review found moderate inter-rater reliability for detecting adverse events and poor reliability for detecting errors, similar to other such studies $(7,15)$. Obviously, if the identification of errors is not reproducible, reliance on error identification to improve patient safety will be problematic (16).

While it is important to recognize the limitations of the data on adverse event rates, it would be short sighted to ignore the learning opportunities. Two key areas where infectious diseases physicians and microbiologists can take advantage of their skills and contribute to advancing the knowledge base in patient safety are the appropriate use of antimicrobials, and applying their epidemiological skills to identifying and preventing adverse events.

There is substantial literature on adverse drug events in hospitalized patients and outpatients. Both studies cited in the IOM report found that adverse drug events were common, and commonly due to antimicrobials $(8,9)$. In a telephone survey of 400 patients following discharge from hospital, 19\% reported having suffered an adverse event, most often an adverse drug event $(66 \%)$, and most commonly (38\%) caused by an antibiotic (17). Although potentially limited by generalizability, a review of medication-related malpractice claims in Boston noted that $9 \%$ were antibiotic-related and $10 \%$ of these were preventable (18). In this study it was estimated that $40 \%$ of preventable inpatient adverse drug events could have been prevented by computerized physician order entry and $64 \%$ by on-site clinical pharmacists (18). In the outpatient setting, although penicillins accounted for only seven of 181 (4\%) adverse events in 661 patients, they had the third highest adverse event rate at 20\% (19). Preventable adverse drug events were due to prescribing errors, one-third of which could have been prevented by computerized prescribing systems. The only predictor of an adverse event was the number of medications that a patient took, suggesting that it may be difficult to identify patients to monitor for the occurrence of an adverse drug event.

Studies in the 1970s estimated that antimicrobial misuse in university and community hospitals is common $(20,21)$. Hecker et al (22) recently looked at the use of antimicrobials in 129 nonintensive care unit patients at a teaching hospital over a two-week period in 2001. They found that 30\% (576 days) of total antimicrobial days of therapy were unnecessary based on available treatment guidelines and one-third of patients received unnecessary antimicrobial therapy. Reasons for the unnecessary regimens were longer than recommended treatment courses, use of antimicrobials in patients with noninfectious syndromes, and treatment of colonizing or contaminating organisms. One-quarter of the unnecessary regimens were associated with adverse events. This study illustrates overuse and misuse as well as the potential for adverse results related to misuse.

Investigators at LDS Hospital in Salt Lake City, Utah demonstrated that a computerized decision-support program for intensive care unit patients resulted in fewer orders for drugs that patients reported allergies to, excess drug doses, antimicrobial-susceptibility mismatches, days of excessive drug dosage and adverse events caused by antimicrobials (23). There were no mortality differences between patients managed with and without the computer assistance. Infectious diseases physicians can play an important role in advising on antimicrobial use at their own institutions, in designing studies that predict situations associated with misuse of antimicrobials, and in identifying strategies to minimize misuse.

The IOM report devoted fewer than two of its 287 pages to infectious disease surveillance, prevention and control, despite identification of wound infections as the second largest category of adverse events in one of the IOM cited references (8) and evidence that hospital infection prevention has demonstrated its effectiveness as a patient safety initiative since the 1970s $(24,25)$. By far, nosocomial infections are the most common complication affecting hospitalized patients, occurring in $5 \%$ to $10 \%$ of admissions (26).

There have been case control studies to identify risk factors for nosocomial infection, as well as randomized controlled studies to evaluate preventive interventions. These have used public health based methods of surveillance using standardized definitions, data analysis, and timely reporting of results to those in a position to effect change. Time and again it has been demonstrated that active surveillance performs better than voluntary reporting to identify adverse events, including nosocomial infections $(26,27)$. In the United States, the National Nosocomial Infections Surveillance (NNIS) system provides benchmark data against which hospitals can compare themselves and implement prevention efforts $(24,28)$. Additionally, NNIS data help to identify changes in incidence, distribution, antibiotic resistance, sites of infection, outcomes, and risk 
factors for infection to guide infection control practitioners in predicting emerging problems (26). Data collected by NNIS have demonstrated a decrease in the incidence of surgical wound infections and infections in intensive care unit patients, which were national health goals for the year 2000 (24). Thomas et al (15), in their study of the reliability of medical record review for estimating adverse event rates, commented on the need for better methods of measurement based on differences in error rates before and after intervention. They predicted that chart review would ultimately prove an unreliable methodology. The elements of the NNIS system critical for infection rate reduction include: voluntary participation and confidentiality for NNIS hospitals; standard definitions and protocols; targeted high-risk populations; site-specific, risk adjusted infection rates comparable across institutions; adequate numbers of trained infection control practitioners; data dissemination to health care providers; and links between monitored rates and prevention efforts (24). The patient safety movement would be well served by embracing the skills that hospital epidemiologists are eager to offer. Canadians would be well served by Health Canada providing increased and stable resources to the successful but limited Canadian Nosocomial Infection Surveillance Program (CNISP) to support the range and depth of surveillance

\section{REFERENCES}

1. Leape L, Epstein AM, Hamel MB. A series on patient safety. N Engl J Med 2002;347:1272-4.

2. Building a Safer System - A National Integrated Strategy for Improving Patient Safety in Canadian Health Care. $<$ http://rcpsc.medical.org/publications/building_a_safer_system_e.pdf> (Version current at March 25, 2004).

3. Health Canada. <http://www.hc-sc.gc.ca/english/care/cpsi_2.html> (Version current at March 25, 2004).

4. Canadian Council on Health Services Accreditation. CCHSA Patient Safety Strategy. A vision for a safe health care system. Canadian Council on Health Services Accreditation; May 2003.

5. Schimmel EM. The hazards of hospitalization. Ann Intern Med 1964;60:100-10.

6. US Institute of Medicine. To Err is Human: Building a Safer Health System. Washington, DC: National Academy Press; 2000.

7. Brennan TA, Leape LL, Laird NM, et al. Incidence of adverse events and negligence in hospitalized patients. Results of the Harvard Medical Practice Study I. N Engl J Med 1991;324:370-6.

8. Leape LL, Brennan TA, Laird N. The nature of adverse events in hospitalized patients. Results of the Harvard Medical Practice Study II. N Engl J Med 1991;324:377-84.

9. Thomas EJ, Studdert DM, Burstin HR, et al. Incidence and types of adverse events and negligent care in Utah and Colorado. Med Care 2000;38:261-71.

10. Thomas EJ, Studdert DM, Newhouse JP, et al. Costs of medical injuries in Utah and Colorado. Inquiry 1999;36:255-64.

11. McDonald CJ, Weiner M, Hui SL. Deaths due to medical errors are exaggerated in Institute of Medicine report. JAMA 2000;284:93-5

12. Hayward RA, Hofer TP. Estimating hospital deaths due to medical errors: Preventability is in the eye of the reviewer. JAMA 2001;286:415-20.

13. Brennan TA. The Institute of Medicine report on medical errors - could it do harm? N Engl J Med 2000;342:1123-5.

14. Gawande AA, Thomas EJ, Zinner MJ, Brennan TA. The incidence and nature of surgical adverse events in Colorado and Utah in 1992. Surgery 1999:126:66-75.

15. Thomas EJ, Lipsitz SR, Studdert DM, Brennan TA. The reliability of medical record review for estimating adverse event rates. Ann Intern Med 2002;136:812-6.

16. Layde PM, Maas LA, Teret SP, et al. Patient safety efforts should focus on medical injuries. JAMA 2002;287:1993-7. activities as performed by the NNIS system. CNISP, a collaborative effort of the Health Care Acquired Infections Division of Health Canada and the Canadian Hospital Epidemiology Committee, has conducted prospective surveillance for methicillinresistant Staphylococcus aureus and vancomycin-resistant enterococci in patients hospitalized in participating acute care facilities for several years. Additionally, it has carried out several short-term surveillance projects examining the incidence or prevalence rates for select hospital-acquired infections. It has not been funded to conduct ongoing surveillance for such important infections as surgical site infections, or infections in intensive care unit patients.

Without minimizing the importance of patient safety, it is critical to remember that there are many other important health issues. In a 2002 patient and public survey in the United States, neither group named medical errors as one of the largest problems in health care (29). In addition to misuse, the current quality focus, overuse and underuse can be categorized as quality problems (30). It is estimated that 700,000 deaths/year in the United States result from gaps in screening, immunization, and reducing risk factors (31). It would indeed be unfortunate if these important issues were overshadowed by the current focus on patient safety, only a small part of population health.

17. Forster AJ, Murff HJ, Peterson JF, Gandhi TK, Bates DW. The incidence and severity of adverse events affecting patients after discharge from the hospital. Ann Intern Med 2003;138:161-7.

18. Rothschild JM, Federico FA, Gandhi TK, Kaushal R, Williams DH, Bates DW. Analysis of medication-related malpractice claims. Arch Intern Med 2002;162:2414-20.

19. Gandhi TK, Weingart SN, Borus J, et al. Adverse drug events in ambulatory care. N Engl J Med 2003;348:1556-64.

20. Maki DG, Schuna AA. A study of antimicrobial misuse in a university hospital. Am J Med Sci 1978;275:271-82.

21. Castle M, Wilfert CM, Cate TR, Osterhout S. Antibiotic use at Duke University Medical Centre. JAMA 1977;237:2819-22.

22. Hecker MT, Aron DC, Patel NP, Lehmann MK, Donskey CJ. Unnecessary use of antimicrobials in hospitalized patients: Current patterns of misuse with an emphasis on the antianaerobic spectrum of activity. Arch Intern Med 2003;163:972-8.

23. Evans RS, Pestotnik SL, Classen DC, et al. A computer-assisted management program for antibiotics and other anti-infective agents. N Engl J Med 1998;338:232-8.

24. Monitoring hospital-acquired infections to promote patient safety - United States, 1990-1999. MMWR 2000;49:149-53.

25. Haley RW, Culver DH, White JW, et al. The efficacy of infection surveillance and control programs in preventing nosocomial infections in US hospitals. Am J Epidemiol 1985;121:182-205.

26. Burke JP. Infection control - a problem for patient safety. N Engl J Med 2003;348:651-6.

27. Samore MH, Evans RS, Lassen A, et al. Surveillance of medical device-related hazards and adverse events in hospitalized patients. JAMA 2004;291:325-34.

28. Scheckler WE. Healthcare epidemiology is the paradigm for patient safety. Infect Control Hosp Epidemiol 2002;23:47-51.

29. Blendon RJ, DesRoches CM, Brodie M, et al. Views of practicing physicians and the public on medical errors. N Engl J Med 2002;347:1933-40.

30. Bodenheimer T. The American health care system - the movement for improved quality in health care. N Engl J Med 1999;340:488-92.

31. Woolf SH. Patient safety is not enough: Targeting quality improvements to optimize the health of the population. Ann Intern Med 2004;140:33-6. 


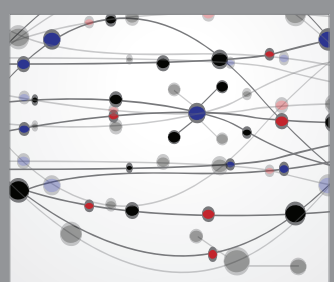

The Scientific World Journal
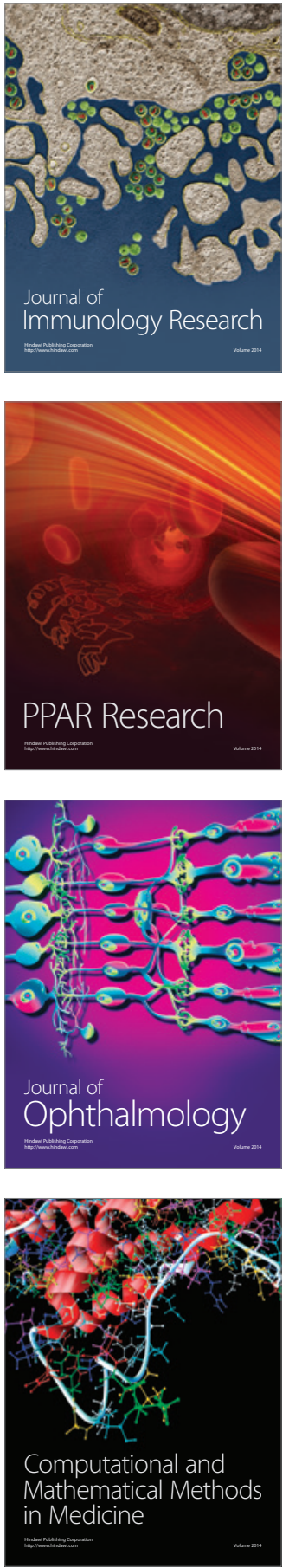

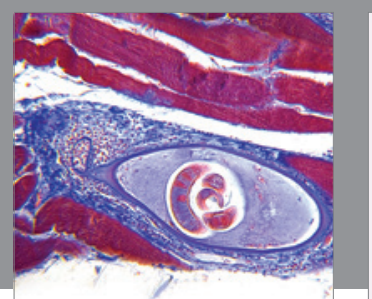

Gastroenterology Research and Practice

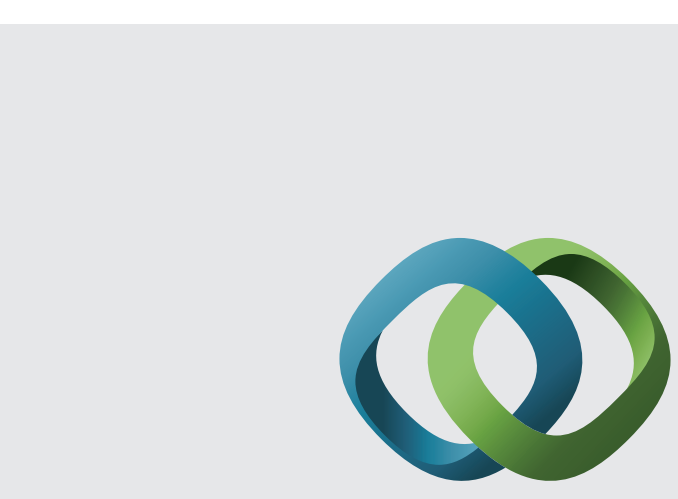

\section{Hindawi}

Submit your manuscripts at

http://www.hindawi.com
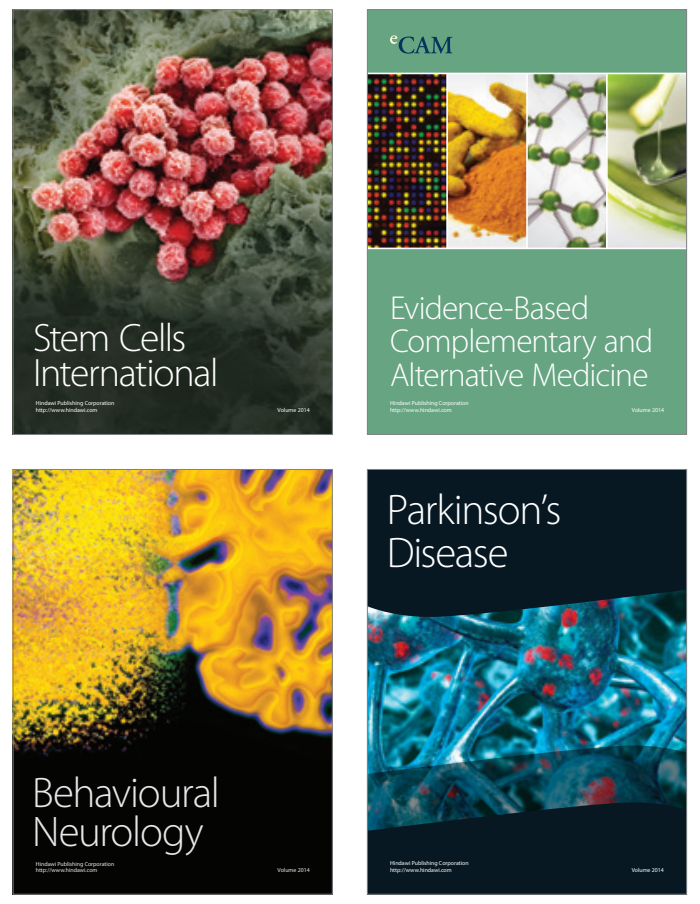
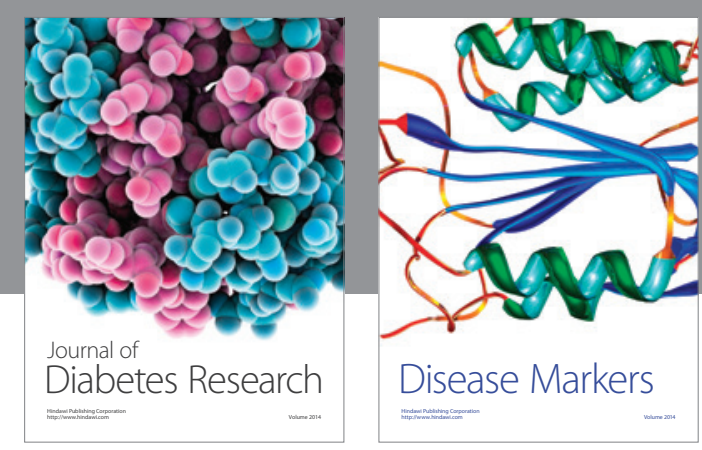

Disease Markers
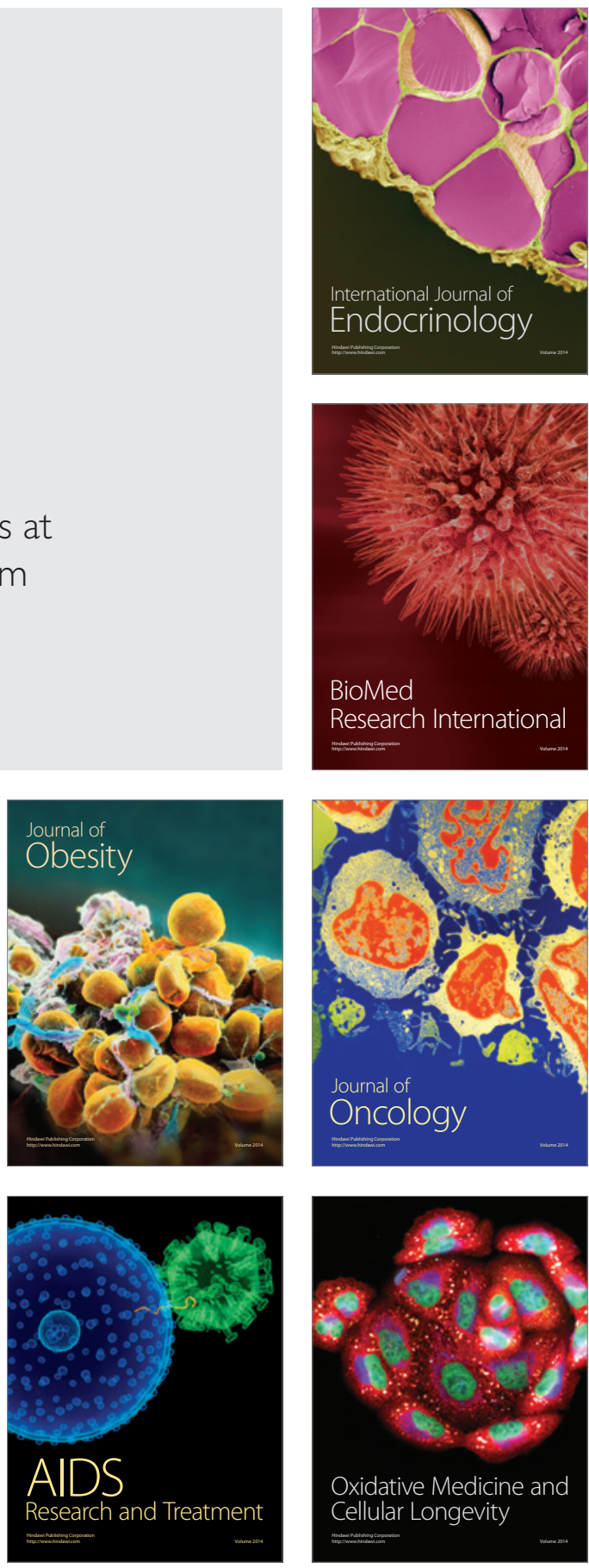